The authors of Cardenas et al. 111:1893-1896 (2021) retracted this article because posterior analyses have identified that the assembled genomes contained a substantial proportion of other fungi beyond the orange rust Puccinia kuehnii, mainly Ascomycetes for one isolate and Ustilaginales for the other (metagenomes). This article was retracted on 11 March 2022.

\section{Draft Genome Sequence Resource for the Orange Rust Pathogen of Sugarcane Puccinia kuehnii}

Daniela E. Cardenas, ${ }^{1,2}$ Jitender Cheema, ${ }^{3}$ Theodora S. Oppelaar, ${ }^{1}$ Martha Hincapie, ${ }^{2}$ Sushma Sood, ${ }^{4}$ Qiaolin Zheng, ${ }^{1}$ Yisel Carrillo-Tarazona, ${ }^{1}$ Jose Huguet-Tapia, ${ }^{5}$ Diane G. O. Saunders, ${ }^{3}$ Jack C. Comstock, ${ }^{4}$ Philippe C. Rott, ${ }^{2,6,7, \dagger}$ and Liliana M. Cano ${ }^{1, \dagger}$

${ }^{1}$ University of Florida, Institute of Food and Agricultural Sciences, Plant Pathology Department, Indian River Research and Education Center, Fort Pierce, FL, 34945, U.S.A.

${ }^{2}$ University of Florida, Institute of Food and Agricultural Sciences, Plant Pathology Department, Everglades Research and Education Center, Belle Glade, FL, 33430, U.S.A.

${ }^{3}$ John Innes Centre, Norwich Research Park, Norwich, U.K.

${ }^{4}$ U.S. Department of Agriculture, Agriculture Research Services, Sugarcane Field Station, Canal Point, FL 33438, U.S.A.

${ }^{5}$ University of Florida, Institute of Food and Agricultural Sciences, Plant Pathology Department, Gainesville, FL 32611, U.S.A.

${ }^{6}$ CIRAD, UMR PHIM, 34090 Montpellier, France

${ }^{7}$ PHIM Plant Health Institute, Univ Montpellier, CIRAD, INRAE, Institut Agro, IRD, Montpellier, France

\section{Abstract}

Puccinia kuehnii is an obligate biotrophic fungal pathogen that causes orange rust of sugarcane, which is prevalent in many countries around the globe. In the United States, orange rust was first detected in sugarcane in Florida in 2007 and poses a persistent and economically damaging threat to the sugarcane industry in this region. Here, we generated the first genome assemblies for two isolates of $P$. kuehnii (1040 and 2143) collected in Florida in 2017 from two sugarcane cultivars, CL85-1040 and CP89-2143, respectively. These two rust genome resources will be of immense value for future genomic studies, particularly further exploration of the predicted secretomes that may help define key pathogenicity determinants for this economically important pathogen.

\section{Genome Announcement}

Puccinia kuehnii is a biotrophic fungal pathogen that causes orange rust of sugarcane and was first reported in the Western Hemisphere in 2007 in Belle Glade, FL (Comstock et al. 2008). Orange rust is an extremely destructive disease responsible for significant losses to sugarcane production in many countries across the globe. P. kuehnii belongs to the order Pucciniales (rust fungi), which is the largest, most complex and diverse group of fungal plant pathogens (Aime et al. 2018; Tavares et al. 2014). Typical of Pucciniales, $P$. kuehnii infects its crop host through asexual urediniospores that germinate on the surface of the sugarcane leaf and the pathogen enters the underlying host tissue through open stomata (Rott et al. 2017). Once inside the host plant, the fungus produces specialized feeding structures called haustoria to deliver effector proteins into host cells to manipulate host processes and promote disease progression (Garnica et al. 2014; Koeck et al. 2011; Lorrain et al. 2019). However, a lack of available genomic resources to date has hampered a systematic analysis of the potential repertoire of these effector proteins in P. kuehnii.

When the first orange rust outbreaks occurred in Florida in 2007 to 2008, several commercially grown sugarcane cultivars were susceptible to the disease while others became susceptible after just a few years. For instance, sugarcane cultivar CL85-1040 was always susceptible, whereas

\section{${ }^{\dagger}$ Corresponding authors: L. M. Cano; Imcano@ufl.edu, and P. C. Rott; philippe.rott@cirad.fr}

First and second authors contributed equally to this work.

The author(s) declare no conflict of interest.

Accepted for publication 17 March 2021. Retracted 11 March 2022.

\section{Funding}

This research was supported by the Florida Sugar Cane League (project 00107475, fund F000057, and fund 660684), and by the National Institute of Food and Agriculture project FLA-IRC005637.

\section{Keywords}

plant pathogen, Puccinia, rust fungus, sugarcane 
cultivar CP89-2143 was initially resistant until 2012 when it exhibited severe rust symptoms (Rice et al. 2014; Sandhu et al. 2018). This suggested virulence changes in the $P$. kuehnii population in Florida. To facilitate future studies aimed at exploring these changes in the virulence profile, we selected two representative $P$. kuehnii isolates for genome sequencing. One was collected in 2016 to 2017 from sugarcane cultivar CL85-1040 in Belle Glade, FL and was named P. kuehnii 1040. The other isolate was collected at the same time in the same location from cultivar CP892143 and was named $P$. kuehnii 2143. Sequences of the ribosomal internal transcribed spacer (ITS) region of these two isolates was obtained using two primer sets as described by Glynn et al. (2010). P. kuehnii species-specific primers Pk1F/Pk1R yielded a fragment of 527 bp (GenBank accessions MW699369-MW699370), whereas the amplicon obtained with $P$. kuehnii/P. melanocephala species-specific primers PkPmF/PkPmR had a size 606 bp (GenBank accessions MW701431 to MW701432). In a blastn search, a 100\% nucleotide sequence identity was observed between isolates 1040, 2143, and P. kuehnii isolate CP80-1743 (GenBank accession EU176009) (Comstock et al. 2008), thus confirming the species identification of isolates 1040 and 2143.

Puccinia kuehnii urediniospores were collected from the lower side of leaves with a glass collector and were used to obtain genomic DNA with the OmniPrep Genomic DNA Isolation Kit (G-Biosciences, Geno Technology Inc.) (Cuomo et al. 2017). Standard sequencing of this genomic DNA was performed with the short read Illumina HiSeq 2500 platform (150-bp paired end reads) and the long read SMRT-Pacific Biosciences platform (PacBio) (10-kb long reads). In addition, DNA extracted from the urediniospores served as a template for whole genome amplification using a multiple displacement amplification (MDA) protocol with the REPLI-g mini kit (Qiagen) (Zhang et al. 2015). MDA libraries were sequenced with Illumina HiSeq 2500 (150-bp paired end reads). All sequenced Illumina raw reads with the HiSeq 2500 platform (150-bp, paired end reads) were quality trimmed using Fastp version 0.20 .0 (Chen et al. 2018). After the trimming, the sequences were also checked for quality using FastQC version 0.11.3 (Andrews 2010). The Illumina raw reads were then analyzed using the GenomeScope webserver (Vurture et al. 2017) to estimate the genome size, repeat content and heterozygosity. P. kuehnii isolates 1040 and 2143 had 3 and $5 \%$ of heterozygosity, respectively. Next, PacBio reads were assembled using Canu v1.4 software (Koren et al. 2017). The error rate of these reads was $1.807 \%$ for isolate $P$. kuehnii 1040 and $1.033 \%$ for P. kuehnii 2143. Illumina paired end short reads (150 bp) were assembled with the MEGAHIT version 1.2 .9 assembler (Li et al. 2015) and had a negligible error rate.

Hybrid genome assemblies that combined the Illumina and PacBio data were constructed and corrected with QuickMerge (version 0.3) along with MUMmer (version 3.23) for merging the assemblies (Chakraborty et al. 2016). To scaffold the contigs and to assist with downstream gene calling, we also generated RNA-seq data from the $P$. kuehnii urediniospore stage. Total RNA was extracted from P. kuehnii urediniospores with the RNeasy Plant Mini Kit (Qiagen) (Dobon et al. 2016) and sequenced with the Illumina HiSeq 2500 platform (150-bp, paired-end reads). Scaffolding of the merged assemblies with the RNA-seq reads was performed using P_RNA_scaffolder (Zhu et al. 2018). We obtained a genome assembly with a genome size of $73.9 \mathrm{Mb}$ with 5,648 scaffolds and $\mathrm{N}_{50}$ value of $93.0 \mathrm{kbp}$ for $P$. kuehnii isolate 1040 (Table 1). The genome of $P$. kuehnii 2143 had a size of $113.0 \mathrm{Mb}$ with 8,502 scaffolds and $\mathrm{N}_{50}$ value of $22.5 \mathrm{kbp}$ (Table 1). Genome annotation completeness was then assessed using BUSCO (benchmarking universal single-copy orthologs) (Simão et al. 2015) with the euk_odb10 database, illustrating $97.1 \%$ completeness for P. kuehnii 1040 and 90.3\% completeness for $P$. kuehnii 2143 (Table 1).

Repeat regions and transposable elements from the genome assemblies were identified using Repeat Modeler and RepeatMasker (Tarailo-Graovac and Chen 2009). A total of 11,698 (5.70\%) and 5,055 (3.03\%) retroelements were found for $P$. kuehnii 1040 and 2143 , respectively. DNA transposons ranged from 530 (isolate 1040) to 5,055 (isolate 2143). Repetitive DNA amounted 5.9\% and $17.4 \%$ for $P$. kuehnii 1040 and 2143 , respectively. The repeat masked genomes were used to predict the final gene models with the BRAKER2 pipeline (Brina et al. 2020). A total of 24,945 proteins (isolate 1040) and 17,143 proteins (isolate 2043) were predicted. Predictions of gene function were performed with the Blastp (Camacho et al. 2009), Interproscan (Jones et al. 2014), and Blast2GO (Götz et al. 2008). Genes of $P$. kuehnii 1040 were attributed to 35,995 gene ontology (GO) terms and $23,445 \mathrm{GO}$ terms for isolate 2143 . To define genes that may encode secreted proteins and thereby likely effector candidates, we annotated proteins for secretion signals and predicted cleavage sites using SignalP v2.0 and v4.1 (Nielsen and Krogh 1998; Petersen et al. 2011). Gene sets were first filtered to remove transmembrane proteins using TMHMM v2.0 (Krogh et al. 2001). A total of 2,660 and 1,423 predicted secreted proteins representing 10.7 and $8.3 \%$ of all protein-coding genes were identified for $P$. kuehnii isolates 1040 and 2143, respectively (Table 1). This was consistent with 
Table 1. Summary statistics of the genomes of Puccinia kuehnii isolates 1040 and 2143

\begin{tabular}{lcc} 
Parameters $^{\text {a }}$ & P. kuehnii $\mathbf{1 0 4 0}$ & P. kuehnii $\mathbf{2 1 4 3}$ \\
Genome size (Mb) & 73.9 & 113.0 \\
Number of scaffolds & 5,648 & 8,502 \\
Longest scaffold (kbp) & 1,054 & 1,367 \\
$\mathrm{~N}_{50}$ Scaffold length (kbp) & 93.0 & 22.5 \\
$\mathrm{~N}_{90}$ scaffold length (kbp) & 5.5 & 7.8 \\
GC content (\%) & 49.3 & 38.5 \\
Retroelements & 11,698 & 21,143 \\
DNA transposons & 530 & 5,055 \\
Repetitive DNA (\%) & 5.9 & 17.4 \\
BUSCO completeness (\%) & 97.1 & 90.3 \\
Number of predicted proteins & 24,945 & 17,143 \\
Secreted proteins (\%) & 10.7 & 8.3 \\
Number of genes with GO terms & 16,791 & 10,813 \\
Number of genes with KEGG annotation & 11,155 & 8,170 \\
\hline
\end{tabular}

${ }^{a}$ BUSCO, benchmarking universal single-copy orthologs; GO, gene ontology; and KEGG, Kyoto encyclopedia of genes and genomes.

the number and proportion of predicted secreted proteins defined for other Pucciniales. For instance, the number of predicted secreted proteins was 1,548 and 1,532 (9\% of all proteins) for $P$. coronata $f$. sp. avenae races $12 \mathrm{NC29}$ and 12SD80 (Miller et al. 2018), 2,146 (10.5\% of all proteins) for $P$. striiformis f. sp. tritici (Pst-78), and 1,857 (11.6\% of all proteins) for P. graminis f. sp. tritici (Xia et al. 2017). The predicted secretome of $P$. kuehnii will contribute to future studies exploring pathogenicity determinants of the two sugarcane rust fungal isolates. These new genomic resources will be of great value to the sugarcane scientific community and researchers working on rust diseases. Sequence reads were deposited at the NCBI database under BioProject SUB7911535 and genome assemblies were deposited at Zenodo (doi:10.5281/zenodo.4422085). Predicted secretome and annotations data are available upon request.

\section{Acknowledgments}

We thank Leonard Fox and his team at the University of Florida, Institute of Food and Agricultural Sciences, Everglade Research and Education Center (EREC) in Belle Glade, for helping us with planting sugarcane cultivars used for the fungal spore collections.

\section{Literature Cited}

Aime, M. C., Bell, C. D., and Wilson, A. W. 2018. Deconstructing the evolutionary complexity between rust fungi (Pucciniales) and their plant hosts. Stud. Mycol. 89:143-152.

Andrews, S. 2010. FastQC: A quality control tool for high throughput sequence data. Babraham Bioinformatics. https://www.bioinformatics.babraham.ac.uk/projects/fastqc

Bruina, T., Hoff, K. J., Lomsadze, A., Stanke, M., and Borodovsky, M. 2020. BRAKER2: Automatic eukaryotic genome annotation with GeneMark-EP+ and AUGUSTUS supported by a protein database. bioRxiv:2020.2008.2010.245134.

Camacho, C., Coulouris, G., Avagyan, V., Ma, N., Papadopoulos, J., Bealer, K., and Madden, T. L. 2009. BLAST+: Architecture and applications. BMC Bioinformatics 10:421.

Chakraborty, M., Baldwin-Brown, J. G., Long, A. D., and Emerson, J. J. 2016. Contiguous and accurate de novo assembly of metazoan genomes with modest long read coverage. Nucleic Acids Res. 44:e147.

Chen, S., Zhou, Y., Chen, Y., and Gu, J. 2018. fastp: An ultra-fast all-in-one FASTQ preprocessor. Bioinformatics 34:1884-i890.

Comstock, J. C., Sood, S. G., Glynn, N. C., Shine, J. M. J., McKemy, J. M., and Castlebury, L. A. 2008. First report of Puccinia kuehnii, causal agent of orange rust of sugarcane, in the United States and Western Hemisphere. Plant Dis. 92:175.

Cuomo, C. A., Bakkeren, G., Khalil, H. B., Panwar, V., Joly, D., Linning, R., Sakthikumar, S., Song, X., Adiconis, X., Fan, L., Goldberg, J. M., Levin, J. Z., Young, S., Zeng, Q., Anikster, Y., Bruce, M., Wang, M., Yin, C., McCallum, B., Szabo, L. J., Hulbert, S., Chen, X., and Fellers, J. P. 2017. Comparative analysis highlights variable genome content of wheat rusts and divergence of the mating loci. G3 (Genes|Genomes|Genetics) 7:361-376.
Dobon, A., Bunting, D. C. E., Cabrera-Quio, L. E., Uauy, C., and Saunders, D. G. O. 2016. The host-pathogen interaction between wheat and yellow rust induces temporally coordinated waves of gene expression. BMC Genom. 17:380.

Garnica, D. P., Nemri, A., Upadhyaya, N. M., Rathjen, J. P., and Dodds, P. N. 2014. The ins and outs of rust haustoria. PLoS Pathog 10:e1004329.

Glynn, N. C., Dixon, L. J., Castlebury, L. A., Szabo, L. J., and Comstock, J. C. 2010. PCR assays for the sugarcane rust pathogens Puccinia kuehnii and $P$. melanocephala and detection of a SNP associated with geographical distribution in $P$. kuehnii. Plant Pathol. 59:703-711.

Götz, S., García-Gómez, J. M., Terol, J., Williams, T. D., Nagaraj, S. H., Nueda, M. J., Robles, M., Talón, M., Dopazo, J., and Conesa, A. 2008. High-throughput functional annotation and data mining with the Blast2GO suite. Nucleic Acids Res. 36:3420-3435.

Jones, P., Binns, D., Chang, H.-Y., Fraser, M., Li, W., McAnulla, C., McWilliam, H., Maslen, J., Mitchell, A., Nuka, G., Pesseat, S., Quinn, A. F., Sangrador-Vegas, A., Scheremetjew, M., Yong, S.-Y., Lopez, R., and Hunter, S. 2014. InterProScan 5: Genome-scale protein function classification. Bioinformatics 30:12361240.

Koeck, M., Hardham, A. R., and Dodds, P. N. 2011. The role of effectors of biotrophic and hemibiotrophic fungi in infection. Cell. Microbiol. 13:1849-1857.

Koren, S., Walenz, B. P., Berlin, K., Miller, J. R., Bergman, N. H., and Phillippy, A. M. 2017. Canu: Scalable and accurate long-read assembly via adaptive k-mer weighting and repeat separation. Genome Res. 27:722-736.

Krogh, A., Larsson, B., von Heijne, G., and Sonnhammer, E. L. 2001. Predicting transmembrane protein topology with a hidden Markov model: Application to complete genomes. J. Mol. Biol. 305:567-580. 
Li, D., Liu, C.-M., Luo, R., Sadakane, K., and Lam, T.-W. 2015. MEGAHIT: an ultra-fast single-node solution for large and complex metagenomics assembly via succinct de Bruijn graph. Bioinformatics 31:1674-1676.

Lorrain, C., Gonçalves dos Santos, K. C., Germain, H., Hecker, A., and Duplessis, S. 2019. Advances in understanding obligate biotrophy in rust fungi. New Phytol. 222:1190-1206.

Miller, M. E., Zhang, Y., Omidvar, V., Sperschneider, J., Schwessinger, B., Raley, C., Palmer, J. M., Garnica, D., Upadhyaya, N., Rathjen, J., Taylor, J. M., Park, R. F., Dodds, P. N., Hirsch, C. D., Kianian, S. F., and Figueroa, M. 2018. De novo assembly and phasing of dikaryotic genomes from two isolates of Puccinia coronata f. $\mathrm{sp}$. avenae, the causal agent of oat crown rust. MBio 9:e01650-17.

Nielsen, H., and Krogh, A. 1998. Prediction of signal peptides and signal anchors by a hidden Markov model. Proc. Int. Conf. Intell. Syst. Mol. Biol. 6:122-130.

Petersen, T. N., Brunak, S., von Heijne, G., and Nielsen, H. 2011. SignalP 4.0: Discriminating signal peptides from transmembrane regions. Nat. Methods 8:785-786.

Rice, R., Baucum, L., and Davidson, W. 2014. Sugarcane variety census: Florida 2013. Sugar J. 77:10-19.

Rott, P., Sood, S., Comstock, J. C., Raid, R. N., Glynn, N. C., Gilbert, R. A., and Sandhu, H. S. 2017. Sugarcane orange rust. Page 4 in: Diseases in Sugarcane (Sugarcane Handbook). University of Florida, Gainesville, FL.

Sandhu, H. S., Singh, M. P., and Gilbert, R. A. 2018. Sugarcane cultivar CP89-2143 descriptive fact sheet. Page 4 in: Agronomy Sugarcane Cultivar Descriptive Fact Sheets Series. University of Florida, Gainesville, FL.
Simão, F. A., Waterhouse, R. M., Ioannidis, P., Kriventseva, E. V., and Zdobnov, E. M. 2015. BUSCO: Assessing genome assembly and annotation completeness with single-copy orthologs. Bioinformatics 31:3210-3212.

Tarailo-Graovac, M., and Chen, N. 2009. Using RepeatMasker to identify repetitive elements in genomic sequences. Curr. Protocols Bioinform. 25:4.10.11-14.10.14.

Tavares, S., Ramos, A. P., Pires, A. S., Azinheira, H. G., Caldeirinha, P., Link, T., Abranches, R., Silva Mdo, C., Voegele, R. T., Loureiro, J., and Talhinhas, P. 2014. Genome size analyses of Pucciniales reveal the largest fungal genomes. Front. Plant Sci. 5:422.

Vurture, G. W., Sedlazeck, F. J., Nattestad, M., Underwood, C. J., Fang, H., Gurtowski, J., and Schatz, M. C. 2017. GenomeScope: Fast reference-free genome profiling from short reads. Bioinformatics 33:2202-2204.

Xia, C., Wang, M., Cornejo, O. E., Jiwan, D. A., See, D. R., and Chen, X. 2017. Secretome characterization and correlation analysis reveal putative pathogenicity mechanisms and identify candidate avirulence genes in the wheat stripe rust fungus Puccinia striiformis f. sp. tritici. Front. Microbiol. 8:2394.

Zhang, R., Ma, Z. H., and Wu, B. M. 2015. Multiple displacement amplification of whole genomic DNA from urediospores of Puccinia striiformis f. sp. tritici. Curr. Genet. 61: 221-230.

Zhu, B.-H., Xiao, J., Xue, W., Xu, G.-C., Sun, M.-Y., and Li, J.-T. 2018. P_RNA_scaffolder: $A$ fast and accurate genome scaffolder using paired-end RNA-sequencing reads. BMC Genom. 19:175. 